\title{
PELATIHAN MANAJEMEN ORGANISASI YAYASAN
}

\author{
Widia Astuti, Rahmat Subur, Teguh Yuwono, Ryan Elfahmi, Jaenudin \\ Universitas Pamulang \\ Email : dosen01265@unpam.ac.id
}

\begin{abstract}
The general objective of this community service activity is to help DKM form and manage a foundation properly so that they can increase the potential of their Human Resources and increase the role of DKM as a young generation in a comprehensive, integrated and directed manner. The method that we will do in community service this time is the cermah method, the discussion method and the demonstration method. From the results of the counseling it was concluded that during the process the DKM administrators were very enthusiastic about participating in community service activities held by Pamulang University lecturers which could be seen from the responses of active participants, paying attention to the speakers and presenters and even getting carried away with the theme Understanding the process of establishing a Foundation and Menparing $H R$.
\end{abstract}

Keywords: Organization Management, Foundation.

\begin{abstract}
Abstrak
Tujuan umum dari kegiatan pengabdian kepada masyarakat ini adalah membantu DKM agar dapat membentuk dan mengelola yayasan dengan baik agar mereka dapat meningkatkan potensi Sumber Daya Manusia yang dimilikinya serta meningkatkan peran DKM sebagai generasi muda secara komprehensif, terpadu dan terarah. Metode yang akan kami lakukan dalam pengabdian kepada masyarakat kali ini dengan metode cermah, metode diskusi dan metode demosntrasi. Dari hasil penyuluhan disimpulkan bahwa selama proses tersebut para pengurs DKM sangat antusias mengikuti kegiatan pengabdian masyarakat yang diadakan oleh dosen Universitas Pamulang yang bisa dilihat dari respon para peserta yang aktif, memperhatikan para narasumber dan pemateri bahkan sampai terbawa suasana dengan tema Memahami proses pembentukan Yayasan dan Menpersiapkan SDM.
\end{abstract}

Kata Kunci : Manajemen Organisasi, Yayasan.

\section{A. PENDAHULUAN}

Dewan Kemakmuran Masjid (DKM), merupakan organisasi islam yang dikelola oleh Jemaah muslim dalam melangsungkan aktivitas di masjid. Setiap masjid yang terkelola dengan baik memiliki DKM dengan strukturnya masing-masing. DKM adalah organisasi sosial muslim wadah pengembangan generasi muda muslim yang tumbuh dan berkembang atas dasar kesadaran dan tanggung jawab sosial dari, oleh dan untuk 
masyarakat terutama generasi muda muslim di wilayah desa/kelurahan dan terutama bergerak di bidang peribadatan islam dan kemakmuran mesjid. Rumusan tersebut diatas dapat dijelaskan sebagai berikut:

Dewan Kemakmuran Mesjid (DKM) adalah suatu organisasi sosial islam yang dikelola oleh jemaah muslim dalam melangsungkan aktivitas di masjid. Sebagai wadah pengembangan generasi muda muslim, DKM merupakan tempat diselenggarakannya berbagai upaya atau kegiatan untuk meningkatkan partisipasi peribadatan umat muslim di masjid. DKM tumbuh dan berkembang atas dasar adanya kesadaran terhadap keadaan dan situasi peribadatan umat muslim di masjid di lingkungannya serta adanya tanggung jawab sosial untuk turut berusaha menanganinya. Kesadaran dan tanggung jawab sosial keislaman tersebut merupakan modal dasar tumbuh dan berkembangnya DKM. DKM tumbuh dan berkembang dari generasi muda muslim, diurus atau dikelola oleh generasi muda muslim dan untuk kepentingan generasi muda dan masyarakat di wilayah desa/kelurahan atau komunitas muslim. Karenanya setiap desa/kelurahan atau komunitas muslim dapat menumbuhkan dan mengembangkan DKMnya sendiri.

Gerakannya di bidang kemakmuran masjid berarti bahwa semua upaya program dan kegiatan yang diselenggarakan DKM ditujukan guna mewujudkan kesejahteraan sosial masyarakat terutama generasi mudanya. Sumber daya manusia yang memiliki skill yang memadai dalam mengelola DKM masih sangat terbatas. Terwujudnya pertumbuhan dan perkembangan kesadaran tanggung jawab sosial setiap generasi muda DKM dalam mencegah, menangkal, menanggulangi dan mengantisipasi berbagai masalah sosial.

Selain itu terbentuknya jiwa dan semangat kejuangan generasi muda DKM yang trampil dan berkepribadian serta berpengetahuan. Berikutnya DKM menumbuhnya potensi dan kemampuan generasi muda dalam rangka mengembangkan keberdayaan DKM. Memotivasi setiap generasi muda DKM untuk mampu menjalin toleransi dan menjadi perekat persatuan dalam keberagaman kehidupan bermasyarakat, berbangsa dan bernegara.

Dalam kesempatan ini kami beberapa dosen dari Universitas Pamulang yang beralamat di jalan Surya Kencana No. 1, Pamulang, Tanggerang Selatan, ingin berbagi ilmu dan pengalaman untuk DKM Mesjid Al Huda Cogreg, Parung melalui Pengabdian Kepada Masyarakat dalam bentuk "PELATIHAN MANAJEMEN ORGANISASI YAYASAN".

\section{B. METODE PELAKSANAAN KEGIATAN}

Metode yang akan kami lakukan dalam pengabdian kepada masyarakat kali ini dengan system:

1. Metode Ceramah

Metode penerangan secara lisan atas bahan pembelajaran kepada sekelompok pendengar untuk mencapai tujuan pembejaaran tertetntu dalam jumlah yang relative besar

2. Metode Diskusi

Proses pelibatan peserta dalam mengemukakan pendapat, mempertahankan pendapat dan pemecahan masalah sehingga mendapatkan kesepakatan diantara mereka

3. Metode Demonstrasi

Metode pembelajaran yang sangat efektif untuk menolong siswa mengungkapkan apa yang menjadi kesepakatan group mereka, lalu dengan keberanian mereka menyampaikan kesepakatan mereka kepada group yang lain dalam bentuk presentasi. 


\section{HASIL DAN PEMBAHASAN}

Kegiatan awal yang dilakukan yaitu berkoordinasi dengan Pengurus DKM Masjid AlHuda yang ada di Daerah kawasan Parung, Kabupaten Bogor. Setelah melakukan diskusi untuk mencari kesepakatan kemudian TIM PKM melakukan koordinasi observasi atas kesediaan untuk pengadaan PKM kepada Pengurus DKM Masjid Al - Huda. Tim PKM memilih karena Salah Satu anggota Kelompok merupakan Anggota Pengurus DKM tersebut disana dan memudahkan Tim PKM untuk kerkoordinasi mengenai PKM tersebut.

Penyuluhan untuk Pelatihan DKM Masjid Al Huda cukup lancar dan peserta dapat mengikutinya dengan baik karena di latar belakangi banyaknya masalah yang dihadapi dengan pelatihan semua berjalan dengan tertib dan lancar. Adapun cara dan tahap-tahap yang kami ajarkan adalah :

1. Identifikasi

2. Penyeleksian

3. Pengorganisasian

4. Pengembangan

5. Evaluasi pengembangan

Maksud dari kegiatan sosialisasi ini adalah mengawali dengan perencanaan dan mengidentifikasi terhadap Masalah Pendirian Yayasan agar dapat mempersiapkan diri dalam menghadapi permasalahan agar tidak bingung dalam menentukan pilihan ke depannya, karena harus di persiapkan sejak dini, perencaan masa depan atau cita-cita perlu menjadi pertimbangan yang sangat penting. Dengan mengetahui perkembangan yayasan, kita bisa merencakan dan mengembangkannya dengan demikian bisa merencanakan dengan matang.

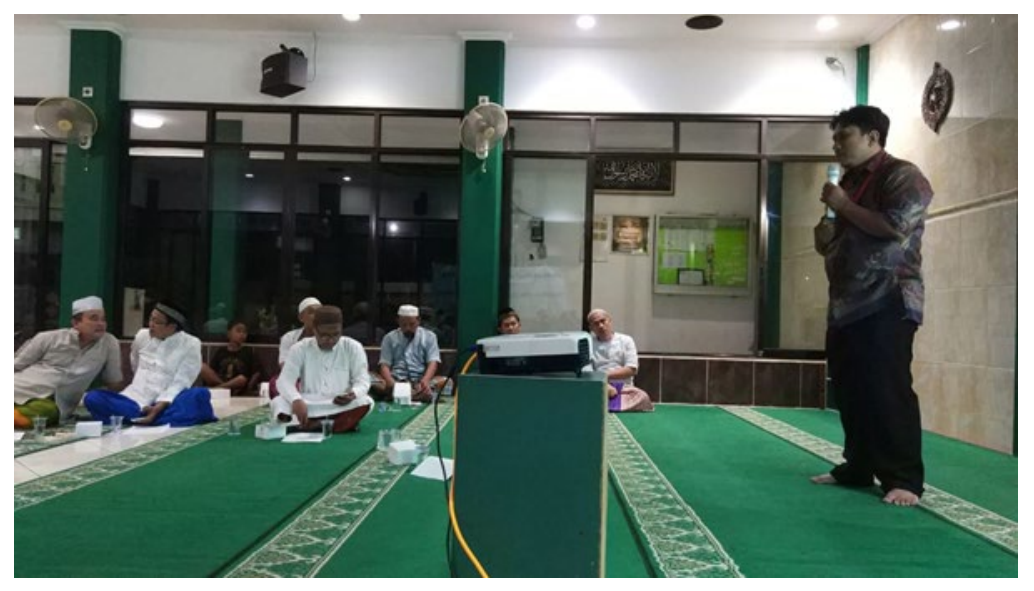

Gambar 1. Narasumber Sedang Memberikan Materi

Sasaran yang ingin dicapai adalah timbulnya kesadaran akan pengetahuan pendirian yayasan dan akan pentingnya mengetahui Fase Pembentukan dan menimbulkan Peluang, agar seseorang dapat belajar dan di kemudian hari bisa bekerja sesuai dengan kemampuan yang dimilikinya sehingga mereka bisa mengembangkan kapabilitas untuk belajar serta bekerja secara optimal dengan penuh antusias. 
DEDIKASI PKM UNPAM

Vol. 1, No. 3, September 2020, Hal (126-130)

@Prodi Manajemen Fakultas Ekonomi Universitas Pamulang

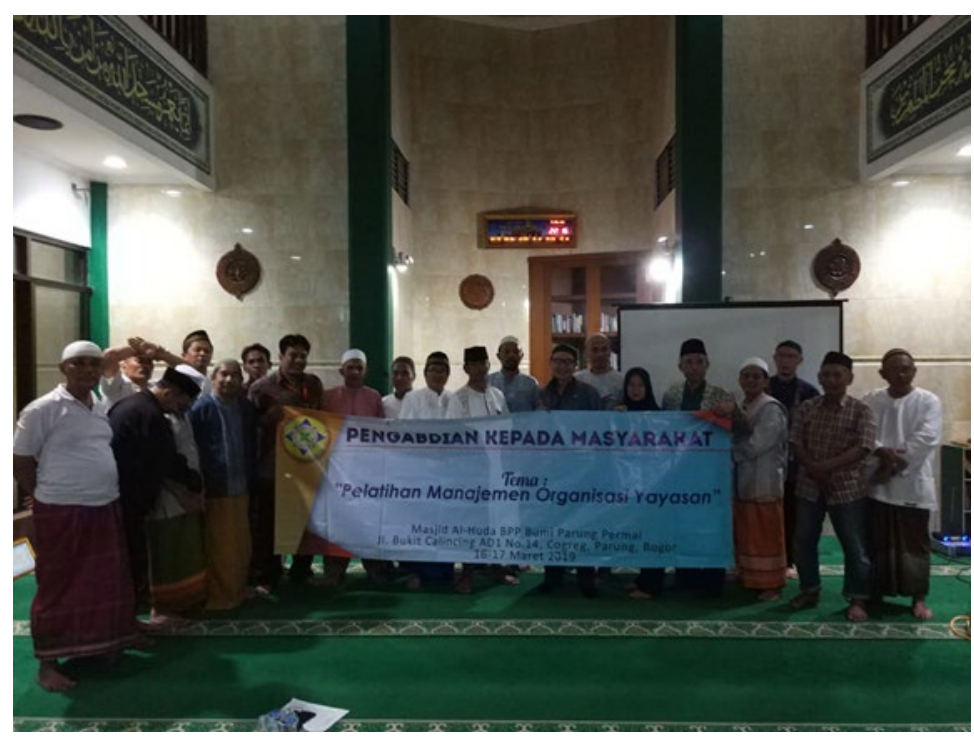

Gambar 2. Foto Tim PKM

\section{KESIMPULAN DAN SARAN}

\section{Kesimpulan}

Dari hasil penyuluhan disimpulkan bahwa selama proses tersebut para pengurs DKM sangat antusias mengikuti kegiatan pengabdian masyarakat yang diadakan oleh dosen Universitas Pamulang yang bisa dilihat dari respon para peserta yang aktif, memperhatikan para narasumber dan pemateri bahkan sampai terbawa suasana dengan tema Memahami proses pembentukan Yayasan dan Menpersiapkan SDM.

Sebagai akhir dari laporan kegiatan Tim PKM Fakultas Ekonomi Program Studi Manajemen Universitas Pamulang di Kabupaten Bogor melakukan PKM di DKM Masjid AlHuda ada beberapa kesimpulan yang dapat dikemukakan.

\section{Saran}

Dalam laporan kegiatan ini mungkin banyak kekurangan yang ada, untuk itu kami berharap masukan dan kritikan dalam rangka perbaikan untuk kegiatan-kegiatan pengabdian masyarakat di masa yang akan datang. Semoga kegiatan pengabdian masyarakat ini dapat bermanfaat bagi masyarakat sekitar lingkungan Universitas Pamulang.

Akhirnya, kami mengucapkan terima kasih kepada seluruh pihak yang telah mendukung kegiatan yang kami laksanakan dan kami mohon maaf apabila dalam laporan ini banyak ditemukan kekurangan.

\section{DAFTAR PUSTAKA}

Aidil Amin Effendy., dkk. (2020). Implementasi Kewirausahaan dan Koperasi di Sekolah Pada SMK Mulia Buana, Parung Panjang - Kab. Bogor. DEDIKASI PKM. Vol. 1. No. 2.

Angga Juanda., dkk. (2020). Menumbuhkan Rasa Gotong Royong Dan Interaksi Sosial Di Kelurahan Pondok Jaya Kota Tangerang Selatan. DEDIKASI PKM. Vol. 1. No. 2. 
Derita Qurbani., Sri Mardiana., dan Riski Dwi Nugroho. (2020). Meningkatkan Minat Dan Potensi Generasi Milenial Khususnya Siswa-Siswi SMK Darussalam Untuk Memulai Bisnis Online Dengan Sistem Dropship. DEDIKASI PKM. Vol. 1. No. 2.

Dumilah, R., Sunarto A., Ahyani., Solihin, D., dan Maulida H. (2020). Pelatihan Pemanfaatan Media Sosial Untuk Promosi Usaha Atau Bisnis Bagi Siswa. DEDIKASI PKM. Vol. 1. No. 1.

Finatariani, E., Setianingsih., Anisa., Zenabia, T., dan Abdurachman, T. A. (2020). Pengelolaan Keuangan Keluarga Dan Pengenalan Dasar-Dasar Investasi Menuju Keluarga Mandiri Bagi Ibu-Ibu Majelis Taklim Al Auladiyah, Tangerang Selatan. DEDIKASI PKM. Vol. 1. No. 2.

Solihin, D. (2020), Faktor-Faktor Yang Mempengaruhi Kinerja Pemasaran Pada PT Prima Ufuk Semesta (Studi Empiris Pada Outlet Rekanan PT. Prima Ufuk Semesta di Wilayah JABODETABEK), Jurnal Semarak, Vol. 3. No. 1.

Solihin, D. (2020), Pengaruh Kepercayaan Pelanggan Dan Promosi Terhadap Keputusan Pembelian Konsumen Pada Online Shop Mikaylaku Dengan Minat Beli Sebagai Variabel Intervening. Jurnal Mandiri. Vol. 4. No. 1.

Solihin, D., dan Wibawanto, E. (2020). Pengaruh Kualitas Pelayanan, Harga, Dan Promosi Terhadap Keputusan Pelanggan Dalam Memilih Klub Basket Satria Indonesia Tangerang Selatan. Jurnal Pemasaran Kompetitif. Vol. 3. No. 3.

Solihin, D. (2019), Pengaruh Current Ratio dan Debt To Equity Ratio Terhadap Return On Asset (ROA) Pada PT Kalbe Farma, Tbk. KREATIF: Jurnal Ilmiah Prodi Manajemen Universitas Pamulang 7 (1), 115-122. 